\title{
Parental Experiences in the Management of Children with Syndromic Craniofacial Diagnoses in Malaysia
}

\author{
Hariri $\mathrm{F}^{\mathrm{a}}$, Norintan Ab Murat $\mathrm{N}^{\mathrm{b}}$, Loh $\mathrm{MY}^{\mathrm{b}}$, Amran $\mathrm{MN}^{\mathrm{b}}$, Chi Adam $\mathrm{KB}^{\mathrm{c}}$ \\ ${ }^{1}$ Department of Oral and Maxillofacial Clinical Sciences, Faculty of Dentistry, University of Malaya, Kuala Lumpur \\ ${ }^{2}$ Department of Community Oral Health \& Clinical Prevention, Faculty of Dentistry, University of Malaya, Kuala Lumpur \\ ${ }^{3}$ Department of Oral Maxillofacial Surgery and Oral Diagnosis, Kulliyyah of Dentistry, International Islamic University of Malaysia
}

Keywords

syndromic craniofacial diagnoses, parental experience, social stigmatisation, Malaysian

Corresponding Author

Asst. Prof Dr Khairul Bariah Chi Adam

Oral Maxillofacial Surgery and

Oral Diagnosis Department

Kulliyyah of Dentistry, IIUM

No Tel: +609-5705521

Email:

Received: 10 November 2020 ; Accepted: 5 February 2021

Doi: https://doi.org/10.31436/imjm.v20i3

\section{ABSTRACT}

INTRODUCTION: Patients with syndromic craniofacial diagnoses (SCD) require coordinated overall management and remain a parental challenge. This study assessed the parental experience and psychological outcome, as well as the evaluation of professional and community support, received in Malaysia. MATERIAL AND METHODS: The Craniofacial Experiences Questionnaire (CFEQ) was used to assess parents of SCD children registered with the Combined Oro-Craniomaxillofacial Clinic in University Malaya Medical Centre, Kuala Lumpur. RESULTS: Thirty parents participated in this study with their children's age ranged from 2 months to 14 years old diagnosed with Apert, Crouzon, and Pfeiffer syndromes, as well as other SCD such as Goldenhar, Pierre Robin, and Nager. The majority of parents felt anxious whenever their child underwent an operation despite having positive perceptions of the outcome. Most respondents did not see the condition as handicap although $6.7 \%$ of parents were embarrassed by their child's appearance. The majority of the respondents were worried about the financial implication, had to be occasionally absent from work due to their child's regular appointments, and felt depressed while only a quarter of respondents socialised less and struggled to meet parenting needs. Most respondents received positive comments, were treated with respect, and obtained adequate support from both health professionals and the community with regards to their childcare. CONCLUSIONS: Although most parents were concerned about their children's condition, only minimal social stigmatisation was noted. Parents were satisfied with the emotional and physical support received from healthcare professionals and the community. Understanding parental experience may contribute to the improvement of multidisciplinary syndromic craniofacial management.

\section{INTRODUCTION}

The spectrum of congenital craniofacial deformities can be categorised based on the involvement of specific structural components of the head and facial regions. When it is in combination with other forms of anomalies in distinct patterns that comprise clinically documented syndromes, they are known as syndromic craniosynostosis. ${ }^{1}$ Syndromic craniosynostosis affects up to 1:30,000 live births and the condition includes Crouzon, Apert, Pfeiffer, Saethre-Chotzen, and Muenke syndromes. 2,3 Their main common characteristics are skull deformity, ocular proptosis, midface hypoplasia, anterior open bite as well as limbs syndactyly.
Syndromic craniofacial diagnoses also presented with severe malocclusion, either class III in syndromic craniosynostosis or class II as in Nager and Treacher Collins, with or without severe dental crowding, cleft conditions, delayed teeth eruption or impaction, and occasionally hyperdontia or hypodontia. ${ }^{4}$

Due to the structural malformation on the head and facial area, parents or children may feel stigmatised. Stigma is a social experience associated with rejection due to a negative perception regarding someone or a group of people. ${ }^{5}$ Children with a deformity in their 
facial areas are commonly teased on their facial differences or speech impairment. ${ }^{6}$ Feelings of melancholy and pity when interacting with a person with a disability may invoke avoidance in normal social relations. Mothers with disabled children claimed that they sometimes felt responsible for their children's differences. Both the family members and the disabled had a significantly higher incidence of emotional distress and social isolation due to stigmatisation. ${ }^{7}$ Some patients even underwent additional surgeries in hope of additional psychological benefits. ${ }^{8}$ Besides functional improvement, facial appearance could be one of the main reasons why parents bring their child to a health care centre at a young age.

Therefore, the birth of a child can be especially difficult as the situation may be emotionally traumatising to some parents because the condition is often detected at birth and requires comprehensive care throughout the patients' childhood years.

It is of utmost importance for parents of children with craniofacial diagnoses to get support from health professionals, especially in the maxillofacial aspect. The sooner an accurate diagnosis is made, the faster the necessary interventions can be done to reduce the complexity of surgical techniques and improve the functional results. Furthermore, children with craniofacial diagnoses usually require a multidisciplinary approach involving a combination of medical and oral healthcare professionals which include oral maxillofacial surgeons, neurosurgeons, plastic surgeons, ophthalmologists, otolaryngologists, orthopaedic surgeon, neurologist, paediatrician, orthodontists, and paediatric dental specialist, among others.

As there is a lack of study regarding parental experience on children with craniofacial diagnoses in Malaysia, and considering the important role of parents in the care of their affected child, this study aimed to 1) assess parents' experience and feelings in the care of children with syndromic craniofacial diagnoses, 2) investigate their perceived stigmatisation experience and 3) evaluate the support gained from health professionals and community in Malaysia.

\section{MATERIAL AND METHODS}

\section{Participants}

This was a cross-sectional study conducted on parents of children with syndromic craniofacial diagnoses. The study was approved by the Medical Ethics Committee, Faculty of Dentistry, University of Malaya (DFOS1709/0032(U)). Participants were recruited from the Combined Oro-Craniomaxillofacial Clinic in the University of Malaya Medical Centre (UMMC) Kuala Lumpur, Malaysia. 40 patients were fitted into the predetermined inclusion criteria and all of them were invited to participate in this study. The inclusion criteria were parents or guardians who have children diagnosed with syndromic craniofacial diagnoses, registered patients at the Combined Craniofacial Clinic, UMMC, and aged 18 years or below. Parents or guardians must also possess a good understanding of either English or Malay language. Non-syndromic cleft lip and palate patients were excluded from this study.

\section{Study Instruments and Procedures}

This study used a series of a self-administered structured questionnaire with the three focused sections which includes: [1] parental experience and feelings, [2] perceived social stigmatisation and, [3] professional and social support. These were mainly derived and modified from Craniofacial Experiences Questionnaire (CFEQ) by Roberts and Shute. ${ }^{9}$ Likert scale of 1 to 4 were used for section one and three $(1=$ strongly disagree, $2=$ disagree, $3=$ agree, $4=$ strongly agree), while Likert scale of 1 to 3 were used for section $2(1=$ almost never, $2=$ sometimes, $3=$ often/always).

The questionnaire underwent a face and content validation process by two reviewers specialised in dental public health and oral maxillofacial surgery followed by pretesting on 10 parents of children with cleft lip and palate to ensure the ease of use, clarity, and readability of the questions and to also estimate the time spent answering the questionnaire. The overall feedback from the parents was positive, and the meantime for questionnaire to completely answer was around 10 minutes. 
The data were collected either through a selfadministered technique or through a phone interview method. The latter technique was used when parents of syndromic craniofacial diagnoses children were unable to come to the combined clinic.

\section{RESULTS}

40 parents of children with craniofacial diagnoses registered at UMMC, 8 parents, however, could not be contacted and 2 refused participation. Hence only 30 participated in this study. Table 1 shows the sociodemographic characteristics of the participants and their children who were diagnosed with craniofacial diagnoses. Parents who participated in the survey were mostly mothers (86.7\%) and of Malay ethnicity (60\%). The mean age of mothers and fathers of the syndromic children were 37.7 and 41.2 years, respectively. With regards to their monthly financial income, most participants (53.3\%) earned more than RM 5,000.

A higher proportion of boys (60\%) than girls (40\%) were diagnosed with craniofacial abnormalities in this study population. Almost three-quarters of the patients were less than 5 years old, with ages ranging from 2 months to 14 years old. Most had Apert Syndrome (40\%), followed by Crouzon (13.3\%) and Pfeiffer (10\%) syndromes. Ten percent of parents were unsure of their child's syndrome. A majority $(90 \%)$ of the children did not have any other chronic diseases.

In terms of the respondents' experiences and feelings in caring for the children with craniofacial diagnoses (Table 2), the majority (90\%) felt anxious whenever their child had to undergo an operation despite having positive perceptions of the outcome of the operation (93.7\%). Most (77\%) did not see the condition as a handicap but a small number of parents were embarrassed by their child's appearances (6.7\%) and dressed their child in clothing to cover up his/her abnormalities (3.3\%). About three-quarters (76.7\%) were worried about their financial spending with regards to their child's management and three-fifths (60\%) of the respondents stated that they had to be absent from work due to their child's regular appointments/surgery.
Table 1 Sociodemographic background of participants and their syndromic child

\begin{tabular}{|c|c|}
\hline $\begin{array}{l}\text { i. Sociodemographic characteristics of } \\
\text { parents }\end{array}$ & $\mathrm{n}(\%)$ \\
\hline \multicolumn{2}{|l|}{ Relationship with child } \\
\hline Father & $4(13.3 \%)$ \\
\hline Mother & $26(86.7 \%)$ \\
\hline $\begin{array}{l}\text { Mother's age } \\
\text { 20-30 years old } \\
31-40 \text { years old } \\
41-50 \text { years old }\end{array}$ & $\begin{array}{l}4(13.3 \%) \\
18(60 \%) \\
8(26.7 \%) \\
\text { Mean age: } 37.70( \pm 6.417) \\
\text { Range: } 22-50 \text { years }\end{array}$ \\
\hline $\begin{array}{l}\text { Father's Age } \\
20-30 \text { years old } \\
31-40 \text { years old } \\
41-55 \text { years old }\end{array}$ & $\begin{array}{l}1(3.3 \%) \\
12(40 \%) \\
17(56.7 \%) \\
\text { Mean age: } 41.17( \pm 6.980) \\
\text { Range: } 29-55\end{array}$ \\
\hline \multicolumn{2}{|l|}{ Ethnicity } \\
\hline Malay & $18(60.0 \%)$ \\
\hline Chinese & $10(33.3 \%)$ \\
\hline Indian & $1(3.3 \%)$ \\
\hline Others & $1(3.3 \%)$ \\
\hline \multicolumn{2}{|l|}{ Monthly income } \\
\hline$<\mathrm{RM} 3000$ & $8(26.7 \%)$ \\
\hline RM3001 - RM5000 & $6(20.0 \%)$ \\
\hline RM5001 - RM10000 & $10(33.3 \%)$ \\
\hline$>$ RM10000 & $6(20.0 \%)$ \\
\hline \multicolumn{2}{|c|}{ ii. Sociodemographic of the child with craniofacial diagnoses } \\
\hline \multicolumn{2}{|l|}{ Gender } \\
\hline Boys & $18(60.0 \%)$ \\
\hline Girls & $12(40.0 \%)$ \\
\hline $\begin{array}{l}\text { Child's age: } \\
5 \text { years and less } \\
6-10 \text { years old } \\
\text { more than } 10 \text { years old }\end{array}$ & $\begin{array}{l}22(73.3 \%) \\
6(6.7) \\
2(6.7 \%) \\
\text { Mean: } 3.27( \pm 4.118)\end{array}$ \\
\hline \multicolumn{2}{|l|}{ Type of Craniofacial Diagnoses } \\
\hline Apert syndrome & $12(40.0 \%)$ \\
\hline Crouzon & $4(13.3 \%)$ \\
\hline Pfeiffer & $3(10.0 \%)$ \\
\hline Goldenhar & $1(3.3 \%)$ \\
\hline Pierre Robin & $1(3.3 \%)$ \\
\hline Nager & $1(3.3 \%)$ \\
\hline $\begin{array}{l}\text { Others (Hemifacial Microsomia, Congenital } \\
\text { Arhinia, etc) } \\
\text { Unsure }\end{array}$ & $\begin{array}{l}5(16.7 \%) \\
3(10.0 \%)\end{array}$ \\
\hline Presence of other chronic disease/s & $3(10.0 \%)$ \\
\hline
\end{tabular}

About $60 \%$ felt depressed when they think about their child's condition and worried about whether their child will be accepted by their peers. A similar proportion of parents $(26.7 \%)$ socialised less due to their children's condition and struggled to meet parenting needs. 
Table 2 Parental experiences and feelings of having or bringing up a child with craniofacial diagnoses

\begin{tabular}{lc}
\hline $\begin{array}{l}\text { Positive and negative statements with regards to parental } \\
\text { experiences and feelings: }\end{array}$ & $\begin{array}{c}\text { Percentage of respondents who } \\
\text { agreed with the statement, } \mathbf{n}(\%)\end{array}$ \\
\hline A. Positive statements: & $28(93.7 \%)$ \\
I believe that operations will bring a positive outcome for my child & $24(83.3 \%)$ \\
I felt positive and calm when doctors told me about my child's condition & $23(76.7 \%)$ \\
I do not see the child as a handicap & $7(23.3 \%)$ \\
I believed that my child will look like normal children after operations & \\
B. Negative statements: & $27(90.0 \%)$ \\
I feel anxious whenever my child underwent operations & $23(76.7 \%)$ \\
I worried about finances & $19(63.3 \%)$ \\
I felt depressed when thinking of the child's condition & $18(60.0 \%)$ \\
I worried about my child being accepted by peers & $18(60.0 \%)$ \\
I often had to be absent from work & $14(46.7 \%)$ \\
I worried about baving another child with a similar condition & $9(30.0 \%)$ \\
I constantly think about my child's condition & $8(26.7 \%)$ \\
I socialised less due to my child's condition & $8(26.7 \%)$ \\
I struggled to meet my child's parenting needs & $6(20.0 \%)$ \\
I blamed myself for my child's condition & $3(10.0 \%)$ \\
I do not want any treatment for my child & $2(6.7 \%)$ \\
I am embarrassed by the child's appearances & $1(3.3 \%)$ \\
I dressed my child in clothing to cover up bis/ her abnormalities & \\
\hline
\end{tabular}

The majority of the respondents agreed that they obtained the appropriate and adequate support from health professionals and the community with regards to caring for their child (Table 4). All respondents (100\%) were 'satisfied with the physical support from the health/ oral health care team' and agreed that 'the health/ oral health care team consisted of experts from appropriate specialties. However, a small number $(13.3 \%)$ felt that they were not 'given adequate advice' when their children were diagnosed with the condition. In terms of getting support from families having children of similar condition, most $(70 \%)$ had acquaintance with parents of children with craniofacial abnormalities and about $67 \%$ of them often met the other parents to exchange thoughts and practical advice.

\section{DISCUSSION}

This study highlighted several important observations with far-reaching implications for the emotional burden and experiences of parents with craniofacial deformity children in this country. Even though only 30 participants were involved, the numbers could safely reflect the response of parents with syndromic

Table 3 Parents' Perceived Stigmatisation Experiences on having a child with craniofacial diagnoses

\begin{tabular}{|c|c|}
\hline $\begin{array}{l}\text { Statements on stigmatisation } \\
\text { experiences }\end{array}$ & $\begin{array}{l}\text { Respondents who } \\
\text { answered 'Often' or } \\
\text { 'Always', n (\%) }\end{array}$ \\
\hline People commented on my child in a positive way & $18(60.0 \%)$ \\
\hline $\begin{array}{l}\text { People treated me with respect whenever I am } \\
\text { with my child }\end{array}$ & $17(56.7 \%)$ \\
\hline People felt relaxed around my child & $14(46.7 \%)$ \\
\hline People showed that they were sorry for my child & $13(43.3 \%)$ \\
\hline Strangers stared at my child & $12(40.0 \%)$ \\
\hline People looked twice or turned around at my child & $11(36.7 \%)$ \\
\hline $\begin{array}{l}\text { Strangers acted surprised/ startled when they see } \\
\text { my child }\end{array}$ & $5(16.7 \%)$ \\
\hline $\begin{array}{l}\text { People did not know what to say when they see } \\
\text { my child }\end{array}$ & $3(10.0 \%)$ \\
\hline $\begin{array}{l}\text { People avoided looking at me whenever I am } \\
\text { with my child }\end{array}$ & $2(6.7 \%)$ \\
\hline People made negative comments about my child & $0(0.0 \%)$ \\
\hline My child was teased & $0(0.0 \%)$ \\
\hline $\begin{array}{l}\text { Spouse / in laws blamed me for my child's } \\
\text { condition }\end{array}$ & $0(0.0 \%)$ \\
\hline
\end{tabular}


craniofacial diagnoses children in Malaysia as the prevalence of this condition is very low at only $0.003 \% .^{3}$

Table 4 Perceptions on getting relevant support from professionals or the community towards caring for their children with craniofacial diagnoses

\begin{tabular}{|c|c|}
\hline $\begin{array}{l}\text { The statement with regards to } \\
\text { professionals and community supports } \\
\text { received }\end{array}$ & $\begin{array}{l}\text { Percentage of } \\
\text { respondents who } \\
\text { agreed with the } \\
\text { statements, } n(\%)\end{array}$ \\
\hline $\begin{array}{l}\text { I am satisfied with the physical support that I get } \\
\text { from the health/ oral health care team. }\end{array}$ & $30(100.0 \%)$ \\
\hline $\begin{array}{l}\text { The health/ oral health care team that managed } \\
\text { my child consisted of experts from appropriate } \\
\text { specialties. }\end{array}$ & $30(100.0 \%)$ \\
\hline $\begin{array}{l}\text { I am satisfied with the emotional support that I } \\
\text { get from the health/ oral health care team. }\end{array}$ & $29(96.7 \%)$ \\
\hline $\begin{array}{l}\text { The health/ oral health care team that managed } \\
\text { my child consisted of an appropriate number of } \\
\text { bealth care professionals. }\end{array}$ & $29(96.7 \%)$ \\
\hline $\begin{array}{l}\text { The health/ oral health care staff displayed a } \\
\text { positive attitude towards my child. }\end{array}$ & $29(96.7 \%)$ \\
\hline $\begin{array}{l}\text { The health/ oral health care team that managed } \\
\text { my child had appropriate knowledge and skills to } \\
\text { care for my child. }\end{array}$ & $29(96.7 \%)$ \\
\hline $\begin{array}{l}\text { The health/ oral health care team made an effort } \\
\text { to create a positive and caring relationship be- } \\
\text { tween them and my family. }\end{array}$ & $28(93.4 \%)$ \\
\hline $\begin{array}{l}\text { The health/ oral health care staff listened sensi- } \\
\text { tively to my feelings and thoughts about my child. }\end{array}$ & $28(93.3 \%)$ \\
\hline $\begin{array}{l}\text { My close relatives and friends provide me with } \\
\text { some emotional support. }\end{array}$ & $28(93.3 \%)$ \\
\hline $\begin{array}{l}\text { I was given adequate advice when my child was } \\
\text { diagnosed with the condition. }\end{array}$ & $26(86.7 \%)$ \\
\hline $\begin{array}{l}\text { I knew parents who have a child with a similar } \\
\text { condition as mine. }\end{array}$ & $21(70.0 \%)$ \\
\hline $\begin{array}{l}\text { I often meet other parents of a child with the same } \\
\text { condition to exchange thoughts and practical } \\
\text { advice. }\end{array}$ & $20(66.7 \%)$ \\
\hline
\end{tabular}

Generally, most parents in this study agreed that they had a positive experience in terms of feelings and experience in taking care of their syndromic children, perceived stigmatisation experience, and support gained from health professionals and the community. This is consistent with a study by Goddard et al. ${ }^{10}$ where parents of children with disabilities did not feel that they were under huge stress in the care of their children. The majority of the parents in this study were positive when they were told by doctors about their child's condition, agreed to the treatments offered by health professionals, and believed that surgery will bring about positive results. However, a minority of them were hoping that their child will look like normal children after the procedure. As such, it is crucial that reasonable outcome should always be reinstated by surgeons to parents of children with complex syndromic craniofacial diagnoses as most of them would be having high expectations towards corrective surgical interventions. ${ }^{11}$
One of the major issues a child with syndromic craniofacial diagnoses has is the need to go through several surgeries as they grow up to correct the affected functional issues and further improve their facial appearances. Most parents in our study admitted that they had to be absent from work to bring their child for medical follow-up, as well as admission for surgeries, which is inconvenient considering that modern families usually function with dual-income. They were also most concerned about the financial impact of caring for their syndromic child. Treatments such as surgery, oral healthcare, speech therapy, or psychological support often add to the financial burden of the family. ${ }^{12}$ In some countries, caregivers of children with disabilities benefit from stipend programmes and respite care and a review has shown that parents rated the cash subsidy as helpful and improved their ability to care for their children. ${ }^{12,13}$ In Malaysia, the Social Welfare Department also provides some financial assistance to parents of persons with a disability, in terms of monthly allowances and tax exemption. However, the availability of publicfunded respite care, where parents can take a break from caregiving and recharge themselves, is still very limited. Fortunately, only a small percentage of parents felt that they struggled to meet their child's financial needs. Less than half of the parents in this study admitted that they constantly think about their child's condition and were worried about having another child with similar defects.

Facial presentation and characteristics are very important and remain an integral part of general health and growth in children. ${ }^{14}$ As such, the emotional cost of having strangers or family members displaying a negative attitude and stigmatisation towards facial deformities may take a toll on the parent's mental wellbeing. Our findings were different as compared to some studies which reported that parents and individuals with the facial difference such as cleft lip and palate who experienced stigma as well as social and structural inequalities due to societal perceptions and misconception. ${ }^{15,16}$ Only less than $5 \%$ of the parents in this study felt the need to cover up their child's facial appearance and were ashamed to socialised due to their child's condition. Most parents reported that they often receive positive comments and people were being respectful about their child's condition. 
The positive stigmatisation experience in our study as compared to other studies can be due to multifactorial such as cultural, belief, and religious philosophy that advocates a positive attitude towards the disadvantaged. ${ }^{16,17}$ The majority of the respondents who were Muslims showed positive stigmatisation experience. This positive attitude was also demonstrated in the study conducted by Ibrahim and Ismail1 ${ }^{18}$ which emphasised the association of the Islamic philosophy that advocates a positive attitude of society's civil responsibility in caring and improving the conditions of the disadvantaged. Such acceptance is positively associated with a psychological outcome such as selfesteem amongst parents. ${ }^{19}$ Therefore, it is evident that religious involvement is associated with better mental health and plays an important role in the acceptance of syndromes in society. ${ }^{20,21}$ It was also shown to affect lowering the level of depression. Religiosity gives guidance through concepts and values on how to see the world and how to act towards it including illnesses and disfigurement. ${ }^{22}$

This study had also shown that parents of syndromic craniofacial diagnoses children had a positive experience with the support gained from health professionals and the surrounding community. ${ }^{11}$ Thus, Buchanan et al. ${ }^{23}$ stressed the need of case by case basis treatment and regular reviews of syndromic craniofacial patients by a multidisciplinary team of health care professionals to allow optimal care thus avoiding any significant morbidity. The need for multidisciplinary support is deemed important as some of the craniofacial patients came with other diseases such as respiratory disease, congenital heart disease as well as diabetes. Regular follow-up, constructive and consistent consultation, as well as complete team, consisted of specialists such as pediatric otorhinolaryngology, pediatric respiratory, pediatric genetics, neurosurgery, oral maxillofacial surgery and oculoplastic are the key factors in the holistic management of children with syndromic craniofacial diagnoses. This could explain the highly satisfied care received as parents were able to obtain professional views and advice from health professionals of different specialties in one visit from a single centre. A multidisciplinary approach should be the focal point in managing craniofacial deformities, where cases are discussed objectively by a group of specialists and explained to the family as a team. The craniomaxillofacial surgical field around the world has evolved to incorporate a multidisciplinary team approach which involves many surgical disciplines that also provides a good platform for dual communication with the patients and family member.

\section{CONCLUSION}

Children with syndromic craniofacial diagnoses requiring comprehensive care remain a parental challenge. Most parents of these children had positive experiences in caring for their child, minimal negative social stigmatisation, and were provided with the necessary professional and community supports. The management provided by a multidisciplinary team of healthcare specialists is a necessity in helping the parents to comprehensively plan for the best outcome of their child's overall growth and development. Further assessment focusing on the experience of healthcare professionals involved in the management of these children is needed as this would facilitate a more holistic understanding of the child's needs and further improve the healthcare service in this specialised field.

\section{CONFLICT OF INTEREST}

None.

\section{ACKNOWLEDGEMENT}

Special thanks to patients and carers in Combined Craniofacial Clinic, UMMC, and not to forget the staff and members of the Craniofacial team.

\section{REFERENCES}

1. Derderian C, Seaward J. Syndromic

Craniosynostosis. Semin Plast Surg. 2012;26(2):6475.

2. Ko JM. Genetic syndromes associated with craniosynostosis. J Korean Neurosurg Soc. 2016;59 (3):187-91.

3. Wang JC, Nagy L, Demke JC. Syndromic craniosynostosis. Facial Plast Surg Clin North Am. 2016;24(4):531-543.

4. Saberi BV, Shakoorpour A. Apert syndrome: report of a case with emphasis on oral manifestations. J Dent. 2011;8(2):90-95. 
5. Scheyett A. The mark of madness: Stigma, serious mental illness and social work. Soc Work Ment Health. 2005;3(4):79-97.

6. Syah SYA, Mirani SA, Sahito MA. Investigating psychosocial impact of cleft lip and palate on patients and parents. Pak Oral Dent J. 2016;36:4244.

7. Green S, Davis C, Karshmer E, Marsh P, Straight B. Living stigma: The impact of labelling, stereotyping, separation, status loss, and discrimination in the lives of individuals with disabilities and their families. Sociol Inq. 2005;75 (2):197-215.

8. Hsiao YJ. Parental Stress in Families of Children With Disabilities. SAGE Journal. 2017;53(4): 201205

9. Roberts RM, Shute R. Living with a craniofacial condition: development of the Craniofacial Experiences Questionnaire (CFEQ) for adolescents and their parents. Cleft Palate Craniofac J. 2011;48(6):727-35.

10. Goddard JA, Lehr R, Lapadat JC. Parents of children with disabilities: Telling a different story. Can J Couns. 2000;34:273-289.

11. Aikins EA, Akinbami BO. Perceptions, expectations, and reactions of caregivers to cleft lip and palate repair in a tertiary hospital. Odontostomatol Trop. 2016;39(155):32-8.

12. Wehby GL, Cassell CH. The impact of orofacial clefts on quality of life and healthcare use and costs. Oral Dis. 2010;16(1):3-10.

13. Coulter ML, Scheuerle J, Laude M, Habal MB. Psychological aspects of parents of children with craniofacial anomalies. J Craniofac Surg. 1991;2 (1):9-17.

14. Di Blasio A1, Mandelli G, Generali I, Gandolfini M. Facial aesthetics and childhood. Eur J Paediatr Dent. 2009;10(3):131-4.

15. Mzezewa S, Muchemwa FC. Reaction to the birth of a child with cleft lip or cleft palate in Zimbabwe. Trop Doct. 2010;40(3):138-40.

16. Adeyemo WL, James O, Butali A. Cleft lip and palate: Parental experiences of stigma, discrimination, and social/structural inequalities. Ann Maxillofac Surg. 2016;6(2):195-203.

17. Johansson B, Ringsberg KC. Parents' experiences of having a child with cleft lip and palate. J Adv Nurs. 2004;47(2):165-173.
18. Ibrahim I, Ismail MF. Muslims with disabilities: psychosocial reforms from an Islamic perspective. J Disabil Religion. 2017;25:1-4.

19. Harrison, M. O., Koenig, H. G., Hays, J. C., EmeAkwari, A. G., \& Pargament, K. I. The epidemiology of religious coping: A review of recent literature. International Review of Psychiatry. 2001;13, 86- 93.

20. Moreira-Almeida, A., Neto, F., \& Koenig, H. (2006). Religiousness and mental health: a review. Revista Brasileira de Psiquiatria, 28(3), 242- 250

21. Nikmanesh Z, Ansari H. Religious Coping Styles, General Health, and Psychological Well-Being Among Mothers of Mentally Disabled Children. Iranian Rehabilitation Journal, 2018; 16(1):3-10. https://doi.org/10.29252/nrip.irj.16.1.3

22. Pearce, M. J. Addressing religion and spirituality in health care systems. In K. I. Pargament, A. Mahoney, \& E. P. Shafranske (Eds.), APA handbooks in psychology®. APA handbook of psychology, religion, and spirituality. 2013;(Vol. 2): An applied psychology of religion and spirituality (p. 527-541).

23. Buchanan E, Xue Y, Xue A, Olshinka A, Lam S. Multidisciplinary care of craniosynostosis. J Multidiscip Healthc. 2017;10:263-270. 